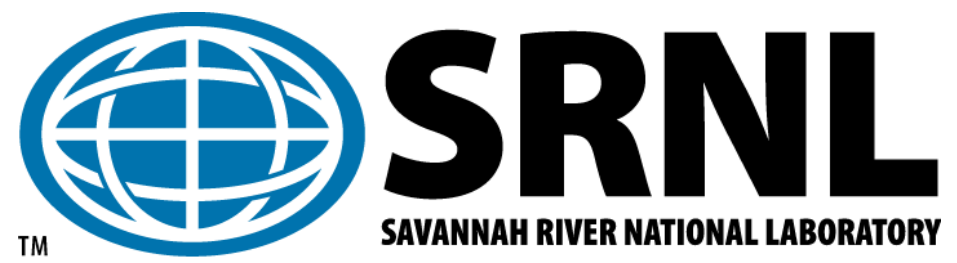

SRNL-STI-2011-00472

\title{
Summary Report for Zinc 65 Contamination Control
}

\author{
Paul Korinko
}

July 14, 2011

\section{Savannah River National Laboratory Savannah River Nuclear Solutions Savannah River Site Aiken, South Carolina}

This document was prepared in connection with work done under Contract No. DE-AC0908SR22470 with the U.S. Department of Energy. By acceptance of this document, the publisher and/or recipient acknowledges the U.S. Government's right to retain a nonexclusive, royalty-free license in and to any copyright covering this document, along with the right to reproduce and authorize others to reproduce all or part of the copyrighted material. 
SRNL-TR-2011-00472

Summary Report for Zinc 65 Contamination Control

Paul Korinko

\section{Table of Contents}

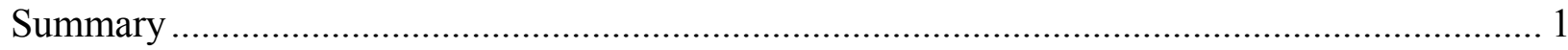

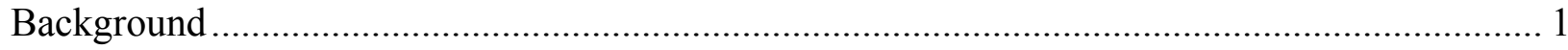

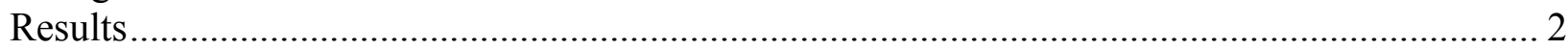

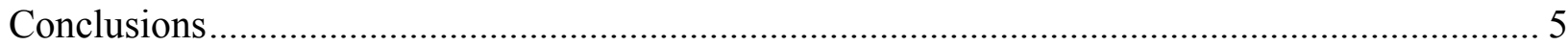

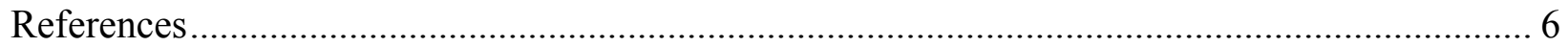

\section{List of Tables}

Table 1. Test Condition and results ............................................................................... 3

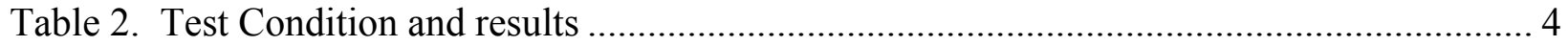

\section{List of Figures}

Figure 1. Effect of pore size on pumping times................................................................ 2

Figure 2. Appearance of zinc deposit on $20 \mu \mathrm{m}$ filters at (a) 60 , (b) 120 and (c) $200^{\circ} \mathrm{C} \ldots \ldots \ldots \ldots . . . .3$

Figure 3. Thermodynamic calculation showing the resultant composition for the Yttrium -

Hydrogen - Zinc system.................................................................................. 4

Figure 4. Copper substrate after $450^{\circ} \mathrm{C}$ exposure in zinc vapor. ......................................... 5 


\section{SRNL-TR-2011-00472}

\section{Summary Report for Zinc 65 Contamination Control}

\section{Summary}

Radioactive zinc, ${ }^{65} \mathrm{Zn}$, was detected after extraction of 215 TPBARs in from TVA reactor fuel cycle 6. A team consisting of Tritium Engineering, Tritium Operations, Tritium Radiation Control, and Savannah River National Laboratory personnel evaluated the risk and response and developed short, medium and long term goals for contamination control. One of the goals was incorporated into site Performance Based Incentive CO 3.4, to optimize the filter geometry and operating conditions for the Tritium Extraction Facility. This goal included a scoping study to determine if the contamination could be contained within the high radiation environment of the furnace module as well. In order to optimize the filters studies were conducted to independently evaluate the effect of pore size on pumping efficiency and zinc trapping efficiency (1). A study was also conducted to evaluate the effect of temperature on the trapping efficiency and adhesion (2). In addition, the potential for chemically trapping zinc in the lithium trap was evaluated using a thermodynamic study (3) followed by preliminary experimental testing (4).

Based on the work that was completed it is determined that a $20 \mu \mathrm{m}$ filter heated to between 120 and $200^{\circ} \mathrm{C}$ will act as an effective physical trap for zinc vapors. It may be possible to chemically react zinc with copper or cobalt to form zinc intermetallic compounds or alloys but additional work under more prototypic conditions are required.

\section{Background}

Radioactive zinc $65\left({ }^{65} \mathrm{Zn}\right)$ has been extracted from irradiated TPBARs at levels that produce a signature greater than background (5). Review of the potential sources of ${ }^{65} \mathrm{Zn}$ from the TPBAR sub-elements indicates that it is an activation product of natural zinc and that it is present as a low level contaminant in several of the TPBAR materials (6). The results from the initial postmortem examination of the piping removed from the TEF, and a literature review of vapor phase deposition indicated that certain conditions may be beneficial to the growth of the zinc whiskers. Consequently $20 \mu \mathrm{m}$ filters heated to $200^{\circ} \mathrm{C}$ were installed in key areas of the TEF process lines (7). The subsequent post-mortem examination of the filters (8), especially gamma scans, indicated that ${ }^{65} \mathrm{Zn}$ had been trapped within these locations, although the deposit morphology was difficult to characterize due to the presence of native $\mathrm{Zn}$ on the filters (9). These results lead TEF to sponsor this effort to optimize filter capturing and evaluate the possibility of capturing zinc within the lithium trap.

An experimental program was initiated to develop and validate conditions that will effectively trap $\mathrm{Zn}$ vapor released during extraction in the TEF. The work was divided into three experimental tasks and a literature/thermodynamics study. The first experimental task was to determine the effectiveness of various pore sizes of filter elements (1) which revealed that $20 \mu \mathrm{m}$ 
filters would be effective to trap the zinc vapor. The second task was to determine the effect of filter temperature on zinc vapor deposition (2) which resulted in a recommendation that the filters be heated to between 120 and $200^{\circ} \mathrm{C}$. The thermodynamics study (3) indicated that copper and cobalt may be effective at trapping zinc in a chemical form while avoiding forming hydrides. If it is possible to capture the contaminants chemically in the lithium trap, then the contamination would remain in the high radiation area, which would reduce potential dose to the worker. The final experimental task was to determine whether the zinc vapors could be chemically bound at conditions typical of the lithium trap (4). The overall approach for capturing the zinc vapors is described in Ref. 9. This report summarizes the results of the experimental testing.

\section{Results}

Figure 1 shows the effect of inserting filters with different pore sizes in the pumping train. It is apparent that filters with pore diameters of 5 to $20 \mu \mathrm{m}$ have little to no effect on the pumping speed and smaller pores adversely affect pumping times.

\section{Average Pump Down Curves}

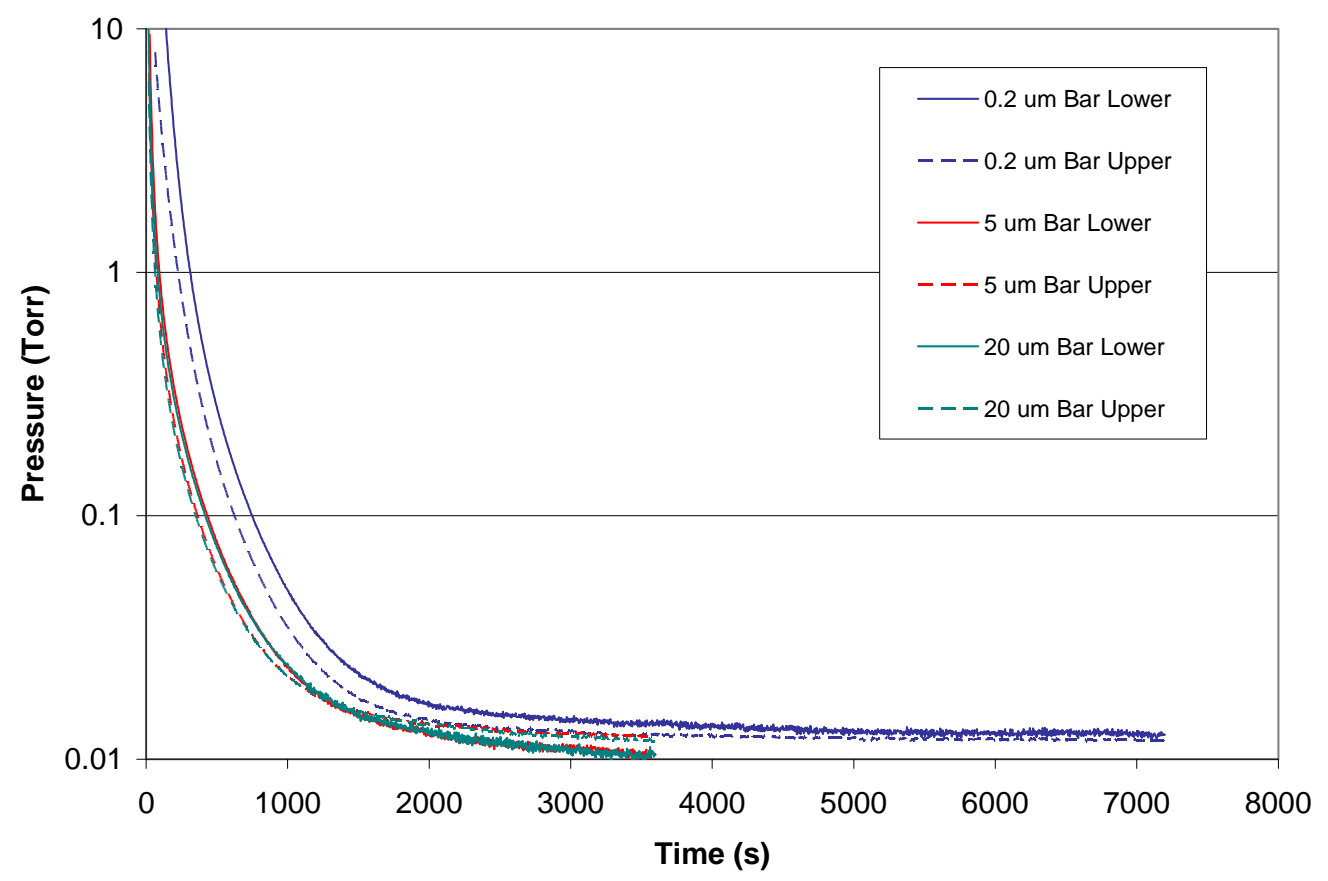

Figure 1. Effect of pore size on pumping times.

The effect of pore size on zinc trapping efficiency was determined by using thermal evaporation of zinc in a glass and metal system. The system was pumped with a scroll pump that would pull the chamber to pressures of 50 to 90 millitorr prior to heating either the zinc containment vessel or the filter holder. The gravimetric data from these experiments are listed in Table 1. There is no apparent difference in the efficiency of zinc vapor trapping due to the amount of scatter in the data. 
Table 1. Test Condition and results

\begin{tabular}{|l|l|l|l|l|}
\hline Filter & $\begin{array}{l}\text { Vessel Temp } \\
\left({ }^{\circ} \mathrm{C}\right)\end{array}$ & $\begin{array}{l}\text { Time } \\
\mathrm{T}>300^{\circ} \mathrm{C}(\mathrm{s})\end{array}$ & $\begin{array}{l}\Delta \text { mass } \\
(\mathrm{mg})\end{array}$ & Comments \\
\hline $0.2 \mu \mathrm{m}-1$ & 333 & 3965 & 0.40 & Old Config. \\
\hline $20 \mu \mathrm{m}-4$ & 340 & 3954 & 1.31 & Old Config. \\
\hline $0.2 \mu \mathrm{m}-2$ & 330 & 7492 & 2.89 & New Config \\
\hline $1 \mu \mathrm{m}-1$ & 325 & 7613 & 1.73 & New Config used Zn \\
\hline $5 \mu \mathrm{m}-1$ & 320 & 6613 & 2.57 & New Config used Zn \\
\hline $10 \mu \mathrm{m}-1$ & 324 & 7689 & 1.49 & New Config used Zn \\
\hline $20 \mu \mathrm{m}-6$ & 325 & 7546 & 1.82 & New Config used Zn \\
\hline $20 \mu \mathrm{m}-7$ & 350 & 8169 & 2.14 & New Config New Zn \\
\hline
\end{tabular}

With the $20 \mu \mathrm{m}$ pore size selected, an optimized temperature was sought. The temperature ranged from 60 to $200^{\circ} \mathrm{C}$. The low temperature was selected based on the current heat trace temperature used for the piping while the upper temperature was based on the temperature limit of the glovebox. Several criteria were used to select the optimized temperature condition. The temperature was to provide the most efficient temperature for zinc capture and also for zinc retention. The typical deposit on the $20 \mu \mathrm{m}$ filters held at 60,120 , and $200^{\circ} \mathrm{C}$ is shown in Figure 2. The deposit is more prevalent on the surface of the filter tested at $60^{\circ} \mathrm{C}$, but this deposit was the easiest to remove based on the simple adhesion test that used.

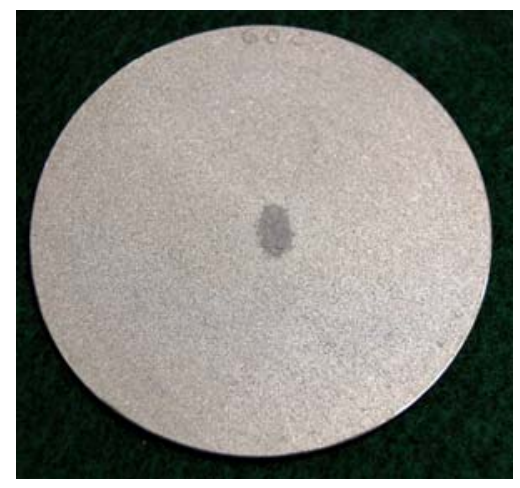

(a)

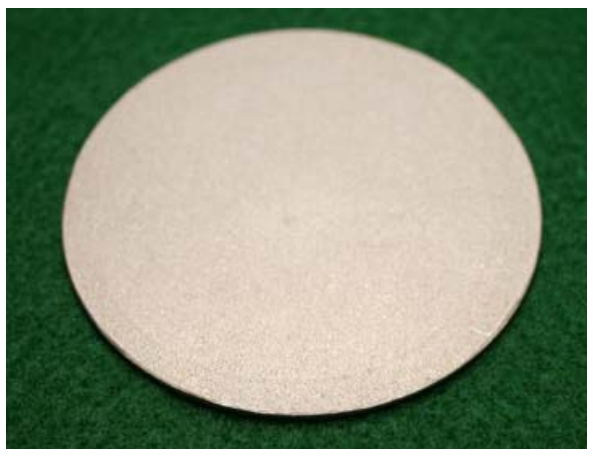

(b)

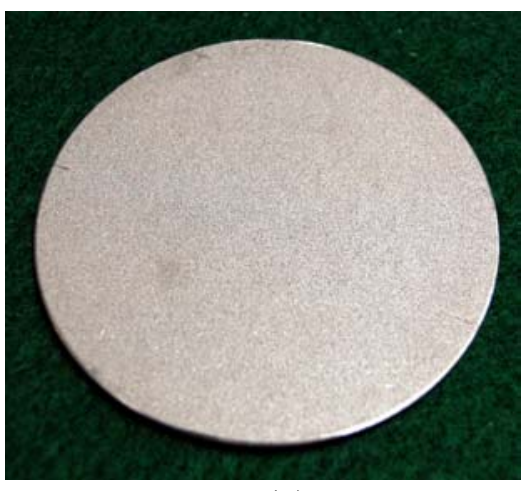

(c)

Figure 2. Appearance of zinc deposit on $20 \mu \mathrm{m}$ filters at (a) 60, (b) 120 and (c) $200^{\circ} \mathrm{C}$.

The deposition weights and adhesion characteristics are listed in Table 2 . These results suggest that $60^{\circ} \mathrm{C}$ is more efficient at trapping the zinc. This result is valid, except that the zinc is poorly adherent to the surface with approximately twice as much material being removed from the $60^{\circ} \mathrm{C}$ sample compared to the 120 and $200^{\circ} \mathrm{C}$. The concern with poorly adherent material is that contamination could spread to other parts of the glovebox during maintenance and other activities. 
Table 2. Test Condition and results

\begin{tabular}{|l|l|l|l|l|l|l|}
\hline $\begin{array}{l}\text { Test } \\
\text { ID }\end{array}$ & Date & $\begin{array}{l}\text { Vessel T } \\
\left({ }^{\circ} \mathrm{C}\right)\end{array}$ & $\begin{array}{l}\text { Filter A } \\
\left({ }^{\circ} \mathrm{C}\right)\end{array}$ & $\begin{array}{l}\text { Filter B } \\
\left({ }^{\circ} \mathrm{C}\right)\end{array}$ & $\begin{array}{l}\Delta \text { mass } \\
(\mathrm{mg})\end{array}$ & $\begin{array}{l}\Delta \text { loss ad. } \\
(\mathrm{mg})\end{array}$ \\
\hline $60-1$ & $1-26$ & 340 & 55 & 52 & 3.8 & 0.8 \\
\hline $60-3$ & $2-10$ & 380 & 57 & 50 & 2.1 & 0.5 \\
\hline $60-4$ & $3-3$ & 384 & 56 & 50 & 3.7 & 0.5 \\
\hline $120-2$ & $2-28$ & 340 & 116 & 96 & 1.6 & 0.1 \\
\hline $120-4$ & $3-1$ & 384 & 116 & 97 & 2.9 & 0.2 \\
\hline $200-1$ & $1-26$ & 340 & 196 & 160 & 2.6 & 0.3 \\
\hline $200-2$ & $2-8$ & 340 & 200 & 165 & $5.5^{*}$ & 0.3 \\
\hline $200-4$ & $2-28$ & 384 & 199 & 149 & 2.4 & 0.2 \\
\hline
\end{tabular}

Notes: "A" refers to thermocouple mounted Above the filter and "B" to the one below. "ad" refers to mass loss during tape adhesion test. *sample was subjected to a double exposure at $400^{\circ} \mathrm{C}$. Missing Test ID are due to poorly executed experiments. The thermocouples were reset on Feb 10, 2011 which resulted in changes in measured vessel temperatures.

Thermodynamic calculations and experiments were conducted that showed that copper and cobalt would capture zinc as compounds without also acting as hydrogen getters. Most materials that had favorable energy of formation for zinc also had a propensity to act as hydrogen getters as well. Figure 3 shows the results of a thermodynamic calculation for zinc and hydrogen in contact with yttrium. This calculation indicates that both zinc and hydrogen would be captured on the yttrium. A further examination of the Y-H diagram indicates that the temperature that hydrogen would be released is over $850^{\circ} \mathrm{C}$ which is well over the conditions in the lithium trap.

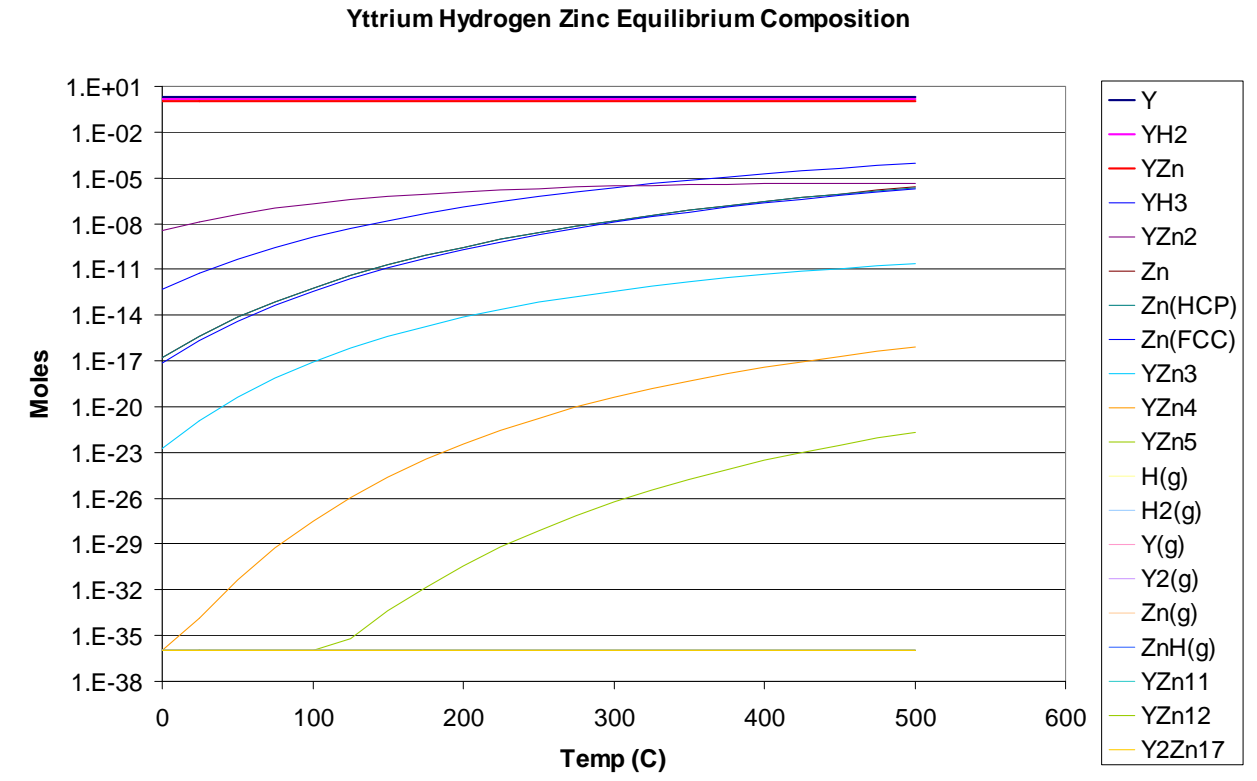

Figure 3. Thermodynamic calculation showing the resultant composition for the Yttrium - Hydrogen - Zinc system. 
A scoping study was conducted to determine if the calculations and literature review could be proven experimentally. Both copper and cobalt components were tested. Zinc was deposited on the copper components but the zinc did not react with the copper, as shown in Figure 4.

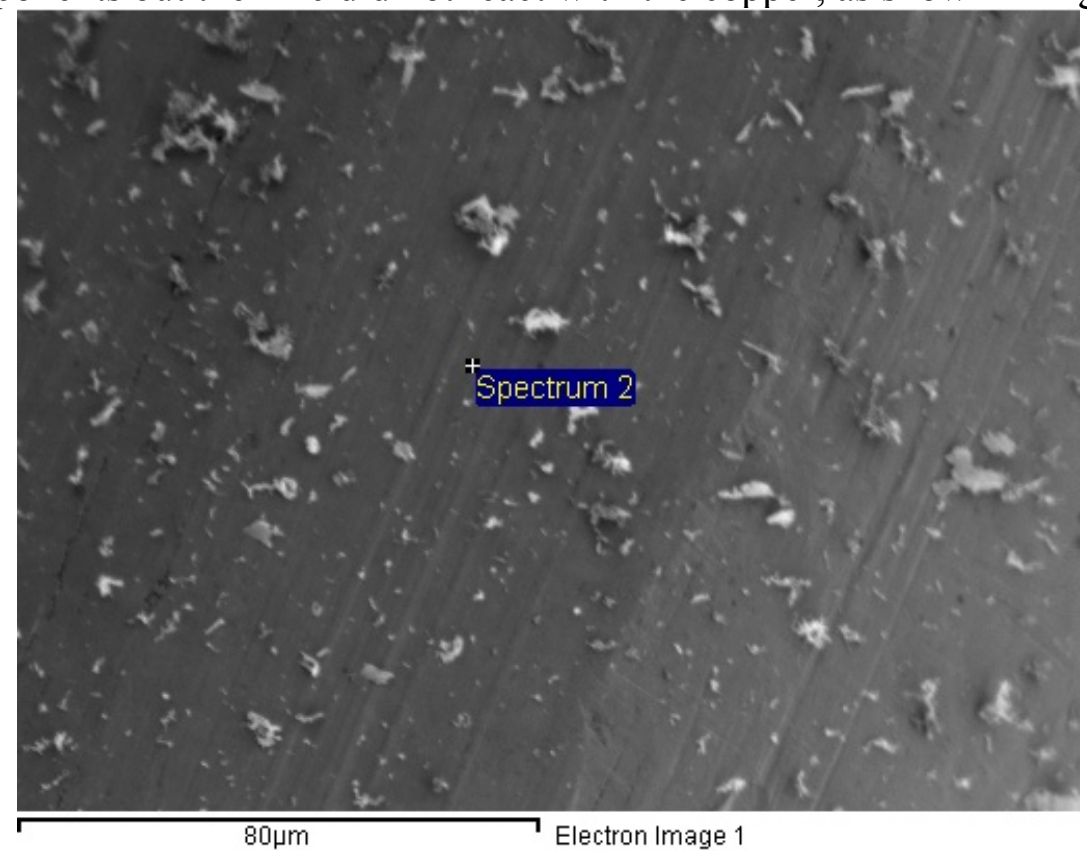

Figure 4. Copper substrate after $450^{\circ} \mathrm{C}$ exposure in zinc vapor.

As can be seen the zinc is present as discrete deposits. Analytical techniques, scanning electron microscopy and x-ray energy dispersion spectroscopy demonstrated that the zinc and copper did not alloy. However, this sample was exposed to a higher shell temperature than what was used for vaporization, yet had a zinc deposit. This result suggests that trapping in the lithium basket may be possible even without chemical binding. Additional work using prototypic conditions, i.e., temperature and pressure of the lithium basket, is needed to validate this possibility.

\section{Conclusions}

Using a filter with a pore diameter of $20 \mu \mathrm{m}$ and holding it at temperature between 120 and $200^{\circ} \mathrm{C}$ will provide a zinc deposition surface that is efficient for trapping in addition to adhesion.

Additional work is needed to develop a suitable substrate for zinc deposition in the lithium trap. Capture of zinc in the lithium trap would be beneficial so that the gamma producing zinc remains in the radiation area rather than being deposited in a glovebox that is designed for beta radiation. In addition, the trap can be disposed of with the TPBARs rather than creating a new waste stream. 


\section{References}

1. SRNL-L4400-2010-00003, Zinc Mitigation Interim Report -- Effect of Pore Size, P. Korinko, 12/2010.

2. SRNL-L4410-2011-00008, Zinc Mitigation Interim Report -- Effect of Filter Temperature on Trapping, 3/2011.

3. SRNL-L4410-2010-00001, Zinc Mitigation Interim Report - Thermodynamic Study, P.S. Korinko, 12/2010.

4. SRNL-L4410-2011-00020, Zinc Mitigation Interim Report - Preliminary Study of Chemically Binding Zinc, P.S. Korinko, 6/2011

5. SRNL-L7100-2008-00001, Analysis of TEF Pipe with ${ }^{65} \mathrm{Zn}$ Contamination P. Korinko, M. Tosten, Z. Nelson, 9/2008.

6. TTP-1-3003, White paper to Address Contamination Issues in TEF, E.F. Love, 2008.

7. SRNL-LM200-2009-00013, Recommendations for TEF to Minimize Further Contamination of ${ }^{65} \mathrm{Zn}$, Paul Korinko, Robert Malstrom, and Andrew Duncan, 4/2009.

8. SRNL-L7100-2010-00008, Examination of TEF Filters for ${ }^{65} \mathrm{Zn}$ Trapping, Paul Korinko, Michael Tosten, Zane Nelson, 2/2010.

9. SRNL-L7100-2010-00034, Examination of New Filter Media used for Zn Coalescing Filters, Paul Korinko, 8/2010.

10. SRNL-L7100-2010-00019, ${ }^{65} \mathrm{Zn}$ Trapping and Containment Optimization, P. Korinko, $5 / 2010$. 